\title{
Correction to: Ponticoccus alexandrii sp. nov., a novel bacterium isolated from the marine toxigenic dinoflagellate Alexandrium minutum
}

\author{
Qiao Yang $\cdot$ Xiaoling Zhang $\cdot$ Lingzhi Li $\cdot$ Ruonan Zhang $\cdot$ Lijuan Feng \\ Jun Mu
}

Published online: 12 February 2018

(C) Springer International Publishing AG, part of Springer Nature 2018

\section{Correction to: Antonie van Leeuwenhoek}

https://doi.org/10.1007/s10482-017-0996-2

Subsequent to the publication of this article, it was noted that one of the culture collection numbers given for the type strain was given in error. Consequently, in the abstract "The type strain is AT2-A ${ }^{\mathrm{T}}$ (CCTCC AB $\left.2016296^{\mathrm{T}}=\mathrm{KCTC} 52626^{\mathrm{T}}\right)$." should read "The type strain is AT2-A ${ }^{\mathrm{T}}$ (CCTCC AB 2016296 ${ }^{\mathrm{T}}=\mathrm{KCTC}$ $\left.62340^{\mathrm{T}}\right)$."

The original article can be found online at https://doi.org/10.1007/s10482-017-0996-2.

Q. Yang $\cdot$ X. Zhang $(\varangle) \cdot$ L. Feng $\cdot$ J. Mu $(\bowtie)$

Laboratory of Marine Environment \& Ecology, College of Marine Science \& Technology, Zhejiang Ocean University, Zhoushan 316022, People's Republic of China e-mail: zhangxiaoling@zjou.edu.cn

J. $\mathrm{Mu}$

e-mail: mujun@zjou.edu.cn

L. Li

East China Sea Fisheries Research Institute, Chinese Academy of Fishery Sciences, Shanghai 2000090, People's Republic of China

\section{R. Zhang}

Center of Research in Life Sciences \& Environmental

Sciences, Harbin University of Commerce,

Harbin 150076, People's Republic of China
Likewise, in the protologue section, "The type strain is AT2-A ${ }^{\mathrm{T}}\left(=\mathrm{CCTCC}\right.$ AB $201696^{\mathrm{T}}=\mathrm{KCTC}$ $52626^{\mathrm{T}}$ ), which is a algal-associated bacterium isolated from the culture of a toxigenic marine dinoflagellate, Alexandrium minutum (Amtk-4) collected from southern Taiwan." should read "The type strain is AT2-A $^{\mathrm{T}}\left(=\right.$ CCTCC AB $201696^{\mathrm{T}}=$ KCTC $\left.62340^{\mathrm{T}}\right)$, which is an algal-associated bacterium isolated from the culture of a toxigenic marine dinoflagellate, Alexandrium minutum (Amtk-4), collected from southern Taiwan." 